\title{
Synthesis and establishment of Amlodipine impurity G reference standard
}

\author{
Ly Dieu Ha ${ }^{1}$, Trang Thi Diem Nguyen ${ }^{2}$, Tri Minh Le ${ }^{1,2}$ \\ ${ }^{1}$ Shool of Medicine, National University HCMC, Vietnam. \\ ${ }^{2}$ Faculty of Pharmacy, University of Medicine and Pharmacy at HCMC, Vietnam.
}

\begin{tabular}{|c|c|}
\hline ARTICLE INFO & ABSTRACT \\
\hline Article history: & \multirow{8}{*}{$\begin{array}{l}\text { Dimethyl-4-(2-chlorophenyl)-2,6-dimethyl-1,4-dihydropyridine-3,5-dicarboxylate which is impurity of } \\
\text { amlodipine besilate was synthesized. Hantzsch condensation of methyl acetoacetate with } 2 \text {-chlorobenzadehyde } \\
\text { in 2-propanol at heated under reflux temperature at } 85{ }^{\circ} \mathrm{C} \text { for about } 10 \text { hours yielded the yellow powder. This } \\
\text { product was purified by column chromatography and the structure was identified by spectroscopic methods (IR, } \\
\text { MS, NMR), that was characterized amlodipine impurity G (dimethyl -4-(2-chlorophenyl)-2,6-dimethyl-1,4- } \\
\text { dihydropyridine-3,5-dicarboxylate). The quality of the impurity was determined by high performance liquid } \\
\text { chromatography HPLC method and validated by guideline of The International Conference on Harmonization } \\
2003 \text { Then this impurity was determined homogeneity and assigned value to establish reference standard as } \\
\text { Appendix } 3 \text { of World Health Organization (WHO technical series } 943 \text {, 2006) and Statistical methods for use in } \\
\text { proficiency testing by inter-laboratory comparison, International Organization for Standardization (ISO 13528), } \\
2005 \text {. }\end{array}$} \\
\hline Received on: 07/05/2017 & \\
\hline Accepted on: 07/07/2017 & \\
\hline Available online: $30 / 10 / 2017$ & \\
\hline Key words: & \\
\hline Hantzsch condensation, & \\
\hline amlodipine impurity G, & \\
\hline WHO, ISO 13528. & \\
\hline
\end{tabular}

\section{INTRODUCTION}

The regulatory agencies and pharmaceutical industries are of increasing concern to the impurities affecting safety, efficacy, and quality of pharmaceutical products. The impurities were to be formed from starting with raw materials, intermediate stages or impurity process. Quality and Safety of The International Conference on Harmonisation 2003, requires that impurities which are present in a drug substance although a quantity exceeding a certain limit, should be characterized, identified and needs to be evaluated both qualitatively and quantitatively. Amlodipine (RS)-3-ethyl-5-methyl-2-[(2-amino ethoxy)methyl]-4-(2-chlorophenyl)-6-methyl-1,4-dihydropyridine -3,5-dicarboxylate is a medication used to treat high blood pressure and coronary artery disease (Burges and Dodd, 1990).

\footnotetext{
* Corresponding Author

Ly Dieu Ha, Shool of Medicine, National University HCMC, Vietnam. Email: hadieuly@gmail.com
}

Chava et al., 2006 reported that 1,4-dihydropyridine derivative were yielded during in the formative stage of the amlodipine, one of degradative products was dimethyl-4-(2chlorophenyl)-2,6-dimethyl-1,4-dihydropyridine-3,5-

dicarboxylate. Harishkumar et al., 2009 published the synthesis of diethyl-2,6-dimethyl-4-substituted phenyl-1,4-dihydropyridine3,5-dicarboxylate by Knoevenagel and Hantzsch condensation. Litvie and co-workers 2007 described Hantzsch condensation reaction of two equivalents of methyl-1,3-aminocrotonate with ( $m$ and $p$ )-methoxybenzaldehyde which resulted in formation of the expected products 2,6-dimethyl-3,5-dimethoxycarbonyl-1-4-( $m$ methoxyphenyl)-1,4-dihydropyridine and 2,6- dimethyl-3,5dimethoxycarbonyl-1-4-( $p$-methoxyphenyl)-1,4-dihydropyridine. However, the synthesis of dimethyl-4-(2-chlorophenyl)-2,6dimethyl-1,4-dihydropyridine-3,5-dicarboxylate (amlodipine impurity G) has not been reported yet, while the monograph of amlodipine salt in Pharmacopoeia (Bristist Pharmacopoeia, 2016 or European Pharmacopoeia 8.8) required for controlling amlodipine impurity $\mathrm{G}$ as related substance. 
The paper reports a synthesis route and establishment of dimethyl-4-(2-chlorophenyl)-2,6-dimethyl-1,4-dihydropyridine3,5-dicarboxylate as impurity reference substance of drug substance of amlodipine in order to quality control of the impurity before manufacturing process.

\section{MATERIALS AND METHODS}

\section{Materials}

Chemicals (AR- Analytical Grade reagents) methyl acetoacetate, 2-propanol 2-chlorobenzaldehyde, ammonium acetate were purchased from Merck Chemicals. Acetonitrile (HPLC grade), methanol (HPLC grade) were purchased from JT. Baker. For column chromatography silica gel (Sigma-Aldrich, 63$200 \mu \mathrm{m})$ was used. Thin layer chromatography was carried out using silica gel 60 F254 aluminum sheets from Merck.

\section{Equipments}

The IR spectrum was recorded by using FT-IR Spectrophotometer Nicolet iS50, Thermo Scientific (KBr dishs). Mass spectrum was recorded on Shimadzu LC/MS IT-TOF. Melting point and purity was determined on Q20 DSC. NMR was performed by using Bruker Mercury $500 \mathrm{MHz}$ spectrometer. TMS was used as an internal reference standard for the proton experiment $(\delta=0.00 \mathrm{ppm})$. The HPLC method was developed on Prominence Liquid Chromatography SPD20-A, Shimadzu, Japan. Gemini-NX $\mathrm{C}_{18}(150 \times 4,6 \mathrm{~mm} ; 5 \mu \mathrm{m})$ column was used.

\section{Methods}

Synthesis of amlodipine impurity $G$ (dimethyl-4-(2chlorophenyl)-2,6-dimethyl-1,4-dihydropyridine-3,5dicarboxylate).

Dissolve $3.9 \mathrm{~g}(0.05 \mathrm{~mol})$ ammonium acetate in $20 \mathrm{ml} 2$ propanol. Add gradually drop by drop in round bottom flask 12.9 $\mathrm{ml}(0.1 \mathrm{~mol}, 13.13 \mathrm{~g})$ methyl acetoacetate and $5.7 \mathrm{ml}(0.05 \mathrm{~mol}$, $7.1 \mathrm{~g})$ 2-chlorobenzaldehyde. Stir vigorously and headed under reflux temperature at $85{ }^{\circ} \mathrm{C}$ for about 10 hours with stirring. The precipitate was filtered and washed with cool methanol $(3 \times 30 \mathrm{~mL})$ and dried in the vacuum at $40{ }^{\circ} \mathrm{C}$ to constant weight. The residue transfered to chromatography column $(10 \times 30 \mathrm{~cm}$, silica gel 40-60 $\mu \mathrm{m})$, 1- $99 \% \mathrm{CH}_{2} \mathrm{Cl}_{2}$-EtOAc and 5- $95 \% \mathrm{CH}_{2} \mathrm{Cl}_{2}$ - EtOAc as eluant to give two fraction AmG1-2. The AmG2 was evaporated to dryness and recrystallized from cool methanol to obtain while powder $(15,04 \mathrm{~g})$.

\section{Method validation and establishment of impurity Reference standard}

The purity of compound AmG2 was checked by TLC and high performance liquid chromatography equipped with Auto Sampler and PDA detector. Mobile phase: $2.3 \mathrm{~g} / \mathrm{L}$ solution of amonium acetate - methanol (30:70 v/v), Column: Gemini-NX (octadecylsilyl silica gel for chromatography)- $\mathrm{C}_{18}(150 \times 4.6 \mathrm{~mm}$, $5 \mu \mathrm{m}$ ) or equivalent; Flow rate: $1.0 \mathrm{~mL} / \mathrm{min}$, Wavelength set up at $273 \mathrm{~nm}$; Injection volume: $20 \mu \mathrm{l}$; Column oven: Ambient; Run time: 3 times of RT of amlodipine impurity G (British Pharmacopoeia, 2016).

The analyse method of synthesized impurity and the various parameters for development and validation according to ICH guidelines (ICHQ2A) were performed. Selectivity and sensitivity was determined by analyzing control samples in replicates $(n=6)$ spiked with the analyte at the lowest level of the calibration standard. Accuracy of the samples was calculated using the calibration curve.

The establishing impurity reference standard was based on the homogeneity; assigned value from two Lab conformed to Good Laboratory Practice (GLP) or ISO/IEC 17025 main principles.

\section{RESULTS AND DISCUSSION}

Synthesis of amlodipine impurity G (dimethyl-4-(2chlorophenyl)-2,6-dimethyl-1,4-dihydropyridine-3,5dicarboxylate).

The reaction Hantzsch condensation of $o, m, p$ methoxylbenzaldehyde isomers with methyl-3-aminocrotonate in propanol showed that the $o$-methoxylbenzaldehyde was compiled much slower during 48 hours, but the mainly obtained product was not 1,4-DHP as the hypothesis of mechanism involves to form derivative 1,4-DHPs of Litvie and co-workers had proved. Addition, Angeles et al (2001) reported that Hantzsch condensation of symmetric 1,4-DHPs are formed as impurites other than to yield 1,4-DHP ring, such as observation of reaction of 2-nitrobenzaldehyde with ammonium hydroxyde and acetoacetic acid ester by Hantzsch, isolated the different compounds including 1,2-dihydropyridine, cyclic amide and substituted hydroxamic acid without the 1,4-DHP product. In the case of our paper, the steric hindrance and electron drawing ability of the substituted 2-chloro on benzaldehyde of amlodipine impurity $\mathrm{G}$ which has not been mentioned, as expected reaction would be Michael addition of the second molecule of methyl acetoacetate rather than to proton transfer and dehydration lead to formation of the imino-Knoevenagel intermediate (Fig.1). An interesting observation the spot trace of imino-knoevenagel intermediate was noted.

By TLC was detected only synthesized impurity in comparison with authentic sample of amlodipine impurity G EPCRS. Thus, the reaction of methyl acetoacetate with 2chlorobenzaldehyde as starting material in propanol gave the Hantzsch condensation was convenient for synthesis amlodipine impurity $\mathrm{G}$ which was higher yield than was expected (yield 78 $\%)$.

AmG2 compound was obtained as while off powder, Rf $\left(\mathrm{CH}_{2} \mathrm{Cl}_{2}-\right.$ EtOAc, $\left.98: 2\right)=0,313 ; \mathrm{mp} 194.10{ }^{\circ} \mathrm{C}$, and purity test on DSC Q20 and HPLC was about $99.85 \%$. The IR absorption bands IR $v_{\max }\left(\mathrm{cm}^{-1}\right): 3306,2947,1702,1651,1493,1231,1020,1118$ and $755 \mathrm{~cm}^{-1}$. HR-MS revealed the molecular formula to be $\mathrm{C}_{28} \mathrm{H}_{27} \mathrm{ClN}_{2} \mathrm{O}_{7} m / z$ [M-H]': 334.0829 (Cal. 335.0814). 


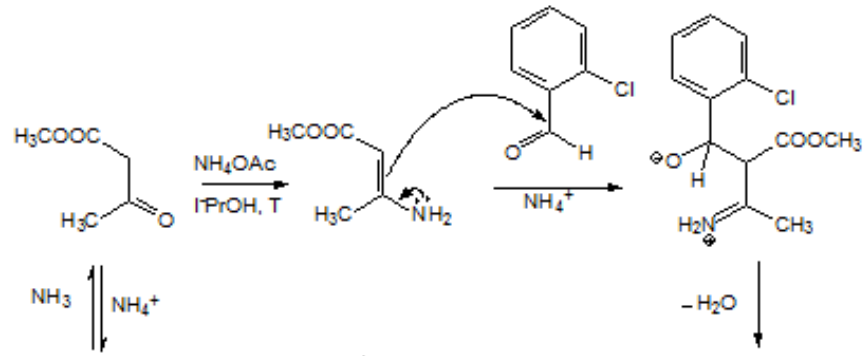<smiles>COC(=O)C(=CC1=CC(=O)C(C(C)=N)=C1)C(=O)OC</smiles><smiles>COC(=O)C1=C(C)N([18OH])C(C)=C(C(=O)OC)C1c1ccccc1Cl</smiles>

Fig. 1: The pathway of synthesis of amlodipine impurity G.

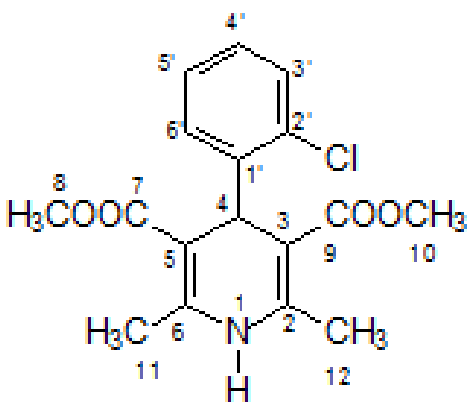

Fig. 2: Structure of amlodipine impurity G.

${ }^{1} \mathrm{H}-\mathrm{NMR}\left(500 \mathrm{MHz}, \mathrm{CDCl}_{3}\right) \delta_{\mathrm{H}} 2.31\left(6 \mathrm{H}, \mathrm{s}, \mathrm{CH}_{3}\right), 3,61$ $\left(6 \mathrm{H}, \mathrm{s}, \mathrm{COOCH}_{3}\right), 5.40(1 \mathrm{H}, \mathrm{s}, \mathrm{CH}), 5.67(1 \mathrm{H}, \mathrm{s}, \mathrm{NH}), 7.03(1 \mathrm{H}$, dt, arom., $J=7.5 \& 1.0 \mathrm{~Hz}, 7.12(1 \mathrm{H}$, t, arom., $J=7.5 \mathrm{~Hz}), 7.24$ (1H, d, arom., $J=7.5 \mathrm{~Hz}), 7.36(1 \mathrm{H}, \mathrm{d}$, arom., $J=7.5 \mathrm{~Hz}) ;{ }^{13} \mathrm{C}$ NMR $\left(125 \mathrm{MHz}, \mathrm{CDCl}_{3}\right): \delta_{\mathrm{C}} 19.4,37.3 ; 50.8,104.0,126.9,127.3$, 129.3, 131.2, 144.0, 145.9, 168.0.

\section{Method validation and establishment of impurity Reference standard}

\section{Method validation}

System suitability

Reference solution: Dissolve $4 \mathrm{mg}$ of amlodipine impurity $G$ EPCRS in acetonitril and dilute to $20.0 \mathrm{~mL}$ with the mobile phase. Test solution: Dissolve $10.0 \mathrm{mg}$ of the substance to be examined in acetonitril and dilute to $10.0 \mathrm{~mL}$ with the mobile phase. Dilute 2.0 $\mathrm{mL}$ of this solution to $10.0 \mathrm{~mL}$ with the mobile phase.

The $\%$ RSD of areas from repeated injects of samples not be more than $2.0 \%$. The SST is suitable for analysis (Table $1 \&$ Fig 3).

Table 1: The parameters of System Suitability Testing.

\begin{tabular}{ccccc}
\hline No Injects & RT (min) & $\begin{array}{c}\mathbf{S}(\boldsymbol{\mu} \mathbf{V} \mathbf{x} \\
\text { second) }\end{array}$ & $\begin{array}{c}\mathbf{A}_{\mathbf{S}} \\
\text { asymetric }\end{array}$ & $\begin{array}{c}\mathbf{N} \\
\text { Theory places }\end{array}$ \\
\hline 1 & 3.872 & 6023226 & 1,272 & 3521 \\
2 & 3.879 & 6033593 & 1.269 & 3530 \\
3 & 3.881 & 6028266 & 1.273 & 3532 \\
4 & 3.883 & 6037178 & 1.274 & 3544 \\
5 & 3.877 & 6030399 & 1.271 & 3526 \\
6 & 3.875 & 6032021 & 1.272 & 3523 \\
Average & 3.878 & 6030781 & 1.272 & 3529 \\
RSD & $\mathbf{0 . 1 0 4}$ & $\mathbf{0 . 0 7 9}$ & $\mathbf{0 . 1 1 4}$ & $\mathbf{0 . 2 3 3}$ \\
\hline
\end{tabular}




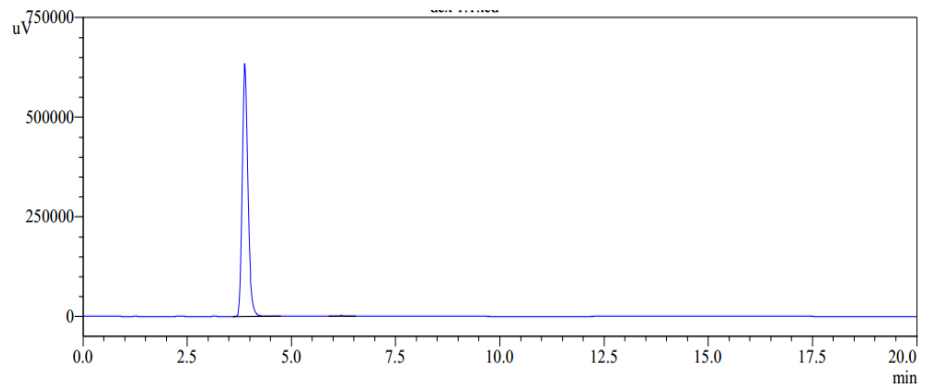

Fig. 3: HPLC Chromatography of amlodipine impurity G.

\section{Specificity Study}

The sample was analyzed in Specific conditions mobile phase Study. Chromatogram of mobile phase doesn't show interference at the retention time of amlodipine impurity G. Therefore this method is specific for determination of amlodipine impurity G.

\section{Linearity study}

Preparation of sample concentrations were about 100 $\mu \mathrm{g} / \mathrm{mL}, \quad 160 \mu \mathrm{g} / \mathrm{mL}, 200 \mu \mathrm{g} / \mathrm{mL}, 240 \mu \mathrm{g} / \mathrm{mL}, 300 \mu \mathrm{g} / \mathrm{mL}$ respectively. Correlation coefficient should not be less than 0.999 (Table 2 \& Fig 4)

The calibration curves were linear over the range of 100.3 to $307.6 \mu \mathrm{g} / \mathrm{mL}$ resulted in the regression equation $\hat{y}=30110 x+15733\left(r^{2}>0.9999\right)$. The LOD and LOQ of the calibration graph were $0.97 \mu \mathrm{g} / \mathrm{ml}$ and $3.23 \mu \mathrm{g} / \mathrm{mL}$, respectively.

Table 2: Linearity Results of compound amlodipin impurity G

\begin{tabular}{cccccc}
\hline $\begin{array}{c}\text { Concentration } \\
(\mu \mathrm{g} / \mathrm{ml})\end{array}$ & 100.3 & 162.4 & 203.9 & 245.4 & 307.6 \\
\hline Average Areas & 30259 & 491302 & 61644 & 74045 & 927072 \\
& 14 & 1 & 05 & 04 & 7 \\
\hline
\end{tabular}

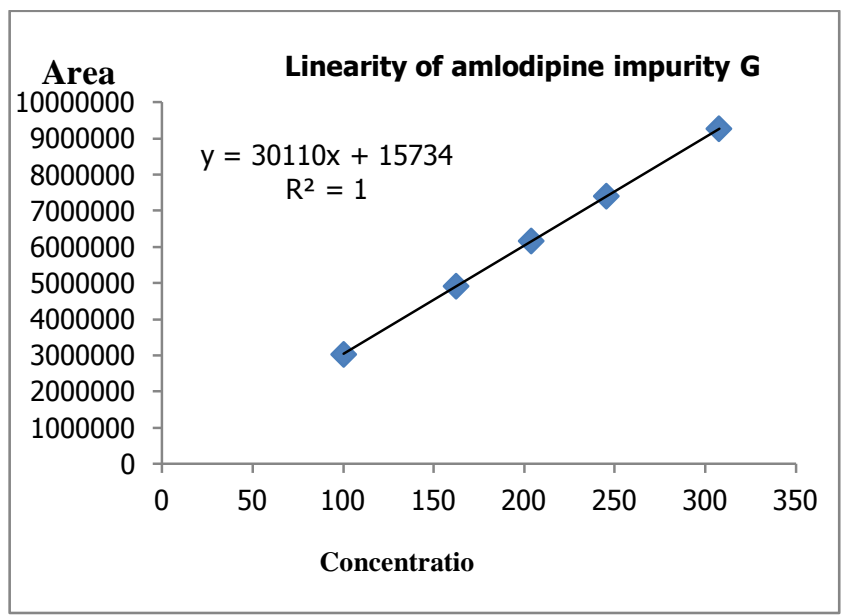

Fig. 4: Linearity of amlodipine impurity G.

\section{Precision (Repeatability):}

The same procedure is repeated to remaining six preparations about $200 \mu \mathrm{g} / \mathrm{ml}$ concentration. \% RSD for the RT and area are tabulated as below in Table 3.
Table 3: Results of Repeatability of amlodipine impurity G by HPLC method.

\begin{tabular}{|c|c|c|c|c|}
\hline \multicolumn{2}{|c|}{$\begin{array}{c}\text { Reference solution } \\
\text { amlodipine impurity G } \\
\text { EPCRS }\end{array}$} & \multicolumn{3}{|c|}{ Synthesis of amlodipine impurity $G$} \\
\hline $\begin{array}{l}\text { Concentrat } \\
\text { ion } \\
(\mu \mathrm{g} / \mathrm{ml})\end{array}$ & $\begin{array}{c}\text { Area of } \\
\text { amlodipine } \\
\text { impurity G } \\
\text { peak } \\
\end{array}$ & $\begin{array}{l}\text { Concen } \\
\text { tration } \\
(\mu \mathrm{g} / \mathrm{ml})\end{array}$ & $\begin{array}{c}\text { Area of } \\
\text { amlodipine } \\
\text { impurity G } \\
\text { peak } \\
\end{array}$ & $\begin{array}{c}\text { Content } \\
\%\end{array}$ \\
\hline \multirow[t]{6}{*}{202.0} & 6059302 & 205.4 & 6062882 & 99.34 \\
\hline & 6061920 & 213.8 & 6314527 & 99.40 \\
\hline & 6011289 & 229.0 & 6780092 & 99.65 \\
\hline & 6014870 & 199.2 & 5887082 & 99.46 \\
\hline & 6041440 & 204.8 & 6027511 & 99.05 \\
\hline & 6036902 & 206.6 & 6095237 & 99.29 \\
\hline \multicolumn{4}{|c|}{ Number of samples } & 6 \\
\hline \multicolumn{4}{|c|}{ Average mean (\%) } & 99.37 \\
\hline \multicolumn{4}{|c|}{ SD } & 0.20 \\
\hline \multicolumn{4}{|c|}{ RSD (\%) } & 0.20 \\
\hline
\end{tabular}

Table 4: Results of Intra- and inter-day precision of amlodipine impurity $\mathrm{G}$ by HPLC method.

\begin{tabular}{ccc}
\hline Number of samples & $\begin{array}{c}\text { Intra-day 1 } \\
\text { Content (\%) }\end{array}$ & $\begin{array}{c}\text { Intra-day 2 } \\
\text { Content (\%) }\end{array}$ \\
\hline 1 & 99.34 & 99.00 \\
2 & 99.40 & 99.26 \\
3 & 99.65 & 99.15 \\
4 & 99.46 & 99.41 \\
5 & 99.05 & 99.25 \\
6 & 99.29 & 99.60 \\
Average & 99.37 & 99.28 \\
SD & 0.20 & 0.21 \\
\% RSD & 0.20 & 0.21 \\
\hline
\end{tabular}

Table 5: Results of accuracy of amlodipine impurity G by HPLC method.

\begin{tabular}{ccccc}
\hline $\begin{array}{c}\text { \% Level } \\
\text { concentration }\end{array}$ & $\begin{array}{c}\text { Area of } \\
\text { amlodipine } \\
\text { impurity } \\
\text { G peak }\end{array}$ & $\begin{array}{c}\text { Concentration } \\
(\mu \mathbf{g} / \mathbf{m l})\end{array}$ & $\begin{array}{c}\text { Concentration } \\
\text { from } \\
\text { regression } \\
\text { equation } \\
(\boldsymbol{\mu} \mathbf{g} / \mathbf{m l})\end{array}$ & $\begin{array}{c}\% \\
\text { Recovery } \\
\mathbf{\pm} \text { SD }\end{array}$ \\
\hline \multirow{2}{*}{50} & 3103426 & 104.2 & 102.5 & $98.6 \pm$ \\
& 2995989 & 100.5 & 99.0 & 0.287 \\
\hline \multirow{2}{*}{100} & 3048975 & 101.8 & 100.7 & $99.8 \pm$ \\
& 6194965 & 205.8 & 205.2 & 0.114 \\
\hline \multirow{2}{*}{150} & 5986070 & 198.9 & 198.3 & $99.0 \pm$ \\
& 6094431 & 202.1 & 201.9 & 1.125 \\
\hline
\end{tabular}

Intra- and inter-day precision

Determination of amlodipine impurity $\mathrm{G}$ concentration in samples ( $n=6$ at each concentration for intra-day and $n=6$ days for interday precision). The $\%$ RSD of areas from six preparations precision level is not more than $2.0 \%$. These results indicate high precision of the proposed methods (table 4 ).

\section{Accuracy}

The accuracy of the test method was demonstrated by preparing recovery samples of at the level of $50 \%, 100 \%$ and 150 $\%$ of target concentration). The recovery of amlodipine impurity $\mathrm{G}$ by HPLC method estimated $99.0 \%$ with RSD $<2 \%$ which comply to accuracy method (table 5). 


\section{Robustness}

The robustness of test method was demonstrated by carrying out Mobile phase variation $\pm 2.0 \%$ (76: $24 \rightarrow 64: 36$ ), flow variation $\pm 10 \%(0.9 \mathrm{~mL}$ to $1.1 \mathrm{~mL} / \mathrm{min})$ the results are tabulated as below in Table 6. Careful validation proved advantages of the method: high sensitivity, accuracy, selectivity and suitability for quality control laboratories.

Table 6: Robustness Study.

\begin{tabular}{lcccc}
\hline Parameters & \multicolumn{2}{c}{ Flow rate $(\mathbf{m L} / \mathbf{m i n})$} & \multicolumn{2}{c}{ Mobile phase $(\mathbf{v} / \mathbf{v})$} \\
\cline { 2 - 5 } & 0.9 & 1.1 & $76: 24$ & $64: 36$ \\
\hline RT & 4.14 & 3.48 & 5.12 & 3.02 \\
Area of amlodipine & $6162882 \pm$ & $5897082 \pm$ & $6262582 \pm$ & $5597102 \pm$ \\
impurity G peak & $0.14 *$ & $0.31 *$ & $0.22 *$ & $0.61 *$ \\
\% Content & 99.05 & 99.31 & 99.11 & 99.41 \\
\hline
\end{tabular}

*SD of $n=3$.

\section{Establishment of impurity Reference standard Homogeneity test}

For a homogeneity check, 12/100 vial of the samples of amlodipine impurity $\mathrm{G}$ packaged in glove-box with nitrogene were selected at random, and the contents of two test portions from each sample were determined. The data are shown in Table.7, together with sample averages and between-test-portion ranges.

The homogeneity was tested by Data analysis-tools of Microsoft excel 2010, Anova-single factor, comparison with values $\mathrm{F}$ and $\mathrm{F}_{\text {crit, }}$, showed that $\mathrm{F}<\mathrm{F}_{\text {crit }}$, so it may be concluded that the samples are adequately homogeneous in the batch.

For the stability check, three of the samples were tested by the same laboratory one month later, and gave an average result of $\mathrm{X}_{1}=99.23 \%$. The difference $X_{1}-X_{o}=0.04 \%$.

Standard deviation for method assessment has been set at 0.211 (Table 9). Assessment criterion for a stability check 0.3. $\mathrm{s}^{*}=$ $0.3 * 0.211=0.063$, so it has to be concluded that the samples are adequately stable.

Table 7: Measurement results for homogeneity check.

\begin{tabular}{cccl}
\hline $\begin{array}{c}\text { Sample } \\
\text { number }\end{array}$ & $\begin{array}{c}\text { Test } \\
\text { portion } \\
\mathbf{1}(\boldsymbol{\%})\end{array}$ & $\begin{array}{c}\text { Test } \\
\text { portion } 2 \\
(\boldsymbol{\%}))\end{array}$ & \multicolumn{1}{c}{ Descriptive Statistics } \\
\hline 1 & 99.28 & 99.03 & \\
2 & 99.36 & 99.44 & \\
3 & 99.30 & 99.39 & Sample average $=99.27 \% ;$ \\
4 & 99.10 & 99.39 & Standard deviation of sample \\
5 & 99.66 & 98.92 & averages SD=0.22 \\
6 & 98.76 & 99.48 & RSD = 0.22 \% \\
7 & 99.06 & 99.20 & Between-samples standard \\
8 & 99.55 & 99.39 & deviation Ss $=0.0004$ \\
9 & 99.35 & 99.42 & \\
10 & 99.52 & 99.07 & \\
11 & 99.01 & 99.42 & \\
12 & 99.32 & 99.17 & \\
\hline
\end{tabular}

Table 8: The parameter of SST from two Lab for assay of amlodipin impurity G.

\begin{tabular}{ccc}
\hline Parameters & Lab1 & Lab 2 \\
\hline $\mathrm{N}>12000$ & 3877 & 3854 \\
$\mathrm{~A}_{\mathrm{s}}: 0.8-1.5$ & 1.315 & 1.320 \\
$\mathrm{RSD} \leq 2 \%$ & $0.11 \%$ & $0.16 \%$ \\
\hline
\end{tabular}

Lab1: Physical Instrument department, Institute of drug Quality Control HCMC. Lab 2: Reference substances department, Institute of drug Quality Control HCMC.
Table 9: Determination of assigned value of amlodipine impurity $G$ by two laboratories, together with values for the expanded uncertainties $(U)$ of the results as reported by the laboratories.

\begin{tabular}{ccccc}
\hline Iteration & $\mathbf{X}_{\mathbf{0}}$ & $\mathbf{X}_{\mathbf{1}}$ & $\mathbf{X}_{\mathbf{2}}$ & $\mathbf{X}_{\mathbf{3}}$ \\
\hline $\mathrm{X}^{*}-1.5 . \mathrm{s}^{*}$ & - & 99.04 & 99.02 & 99.02 \\
$\mathrm{X}^{*}+1.5 . \mathrm{s} *$ & - & 99.61 & 99.65 & 99.65 \\
Average & 99.343 & & & \\
Standard & 0.194 & & & \\
deviation & & & $\mathbf{9 9 . 3 3 7}$ & $\mathbf{9 9 . 3 3 7}$ \\
New X* & $\mathbf{9 9 . 3 2 5}$ & $\mathbf{9 9 . 3 3 7}$ & $\mathbf{0 . 2 1 1}$ & $\mathbf{0 . 2 1 1}$ \\
New s* & $\mathbf{0 . 1 9 3}$ & $\mathbf{0 . 2 1 1}$ & & \\
\hline
\end{tabular}

\section{Assigned value}

After checking the suitability system of two lab (Table $8)$, the assigned value was determined. The result showed that there is no change the values of $x^{*}$ and $s^{*}$ from one iteration to the third modified data. So convergence may be assumed and the assigned value was $99.34 \%$, with the uncertainty

$$
U_{x}=1.25 s * / \sqrt{p}=0.076 \text {. }
$$

\section{CONCLUSION}

In conclusion, a facile synthetic route to amlodipine impurity $\mathrm{G}$ has been developed with overall $78 \%$ yield starting from 2-chlorobenzaldehyde, methyl acetoacetate and amonium salt in propanol and heated under reflux temperature at $85{ }^{\circ} \mathrm{C}$ for about 10 hours with stirring. The product was purified and structural elucidation by spectroscopic techniques to confirm its of dimethyl4-(2-chlorophenyl)-2, 6-dimethyl-1,4- dihydropyridine-3,5dicarboxylate.

The simple, accurate and precise RP-HPLC method for the determination of amlodipine impurity G as BP 2016 was verified. The establishment of authentic sample was carried out, it is concluded that the amlodipine impurity $\mathrm{G}$ (99.34\% as is) may be recommended as reference standard for routine and qualitycontrol analysis in the drug substances and formulations.

\section{Financial support and sponsorship: Nil.}

Conflict of Interests: There are no conflicts of interest.

\section{REFERENCES}

Bristish Pharmacopoeia 2016, Ph.Eur monograph 1491, CDrom.

Harishkumar DR, Naira N, Manjunath G. Synthesis and invitro calcium channel blocking activity of symmetrical and unsymmetrical substituted 1,4-dihydropyridines. Asian journal of Chemistry, 2009, 6 (21): 4357-4365.

E. Angeles, H. Santillan, I. Martine. Rearrangement of $o$ nitrobenzaldehyde in the Hantzsch reaction, Molecules 2001; 6: 683-693.

The International Conference on Harmonisation, Quality and Safety, 2003, Volume 1, Eu adopted by CPMP/ICH/2738/99,

ISO 13528, Statistical methods for use in proficiency testing by interlaboratory comparison 2005-09-01. ISO copyright office, Published in Switzerland. 
M. Litvie, F.M. Litvie, I. Cepanec, V. Vinkovie, Hantzsch synthesis of 2,6-dimethyl-3,5-dimethoxycarbnyl-1-(o-methoxyphen)-1,4dihydropyridien; a Novel cyclisation leading to un unusual formation of 1- amino-2-methoxycarbonyl-3,5-bis (o-methoxylphenyl)-4-oxacyclog]hexan-1-en. Molecules, 2007; 12: 2546-2558.

Burges RA, Dodd MG. Amlodipine. Cardiovasc Drug Rev. $1990 ; 8: 25-44$.

Chava S, Ramanjaneyulu GS, Rao KB. Process for the preparation of pure amlodipine, Japan Patent WO2006003672 A1, 2006.

WHO Expert Committee on Specifications for Pharmaceutical Preparations: forty-first report, 2006 (WHO technical report series; No. 943), Appendix 3, WHO Press, World Health Organization, 1211 Geneva 27, Switzerland.

How to cite this article:

Ha LD, Nguyen LTD, Le TM. Synthesis and establishment of Amlodipine impurity G reference standard. J App Pharm Sci, 2017; 7 (10): 105-110. 